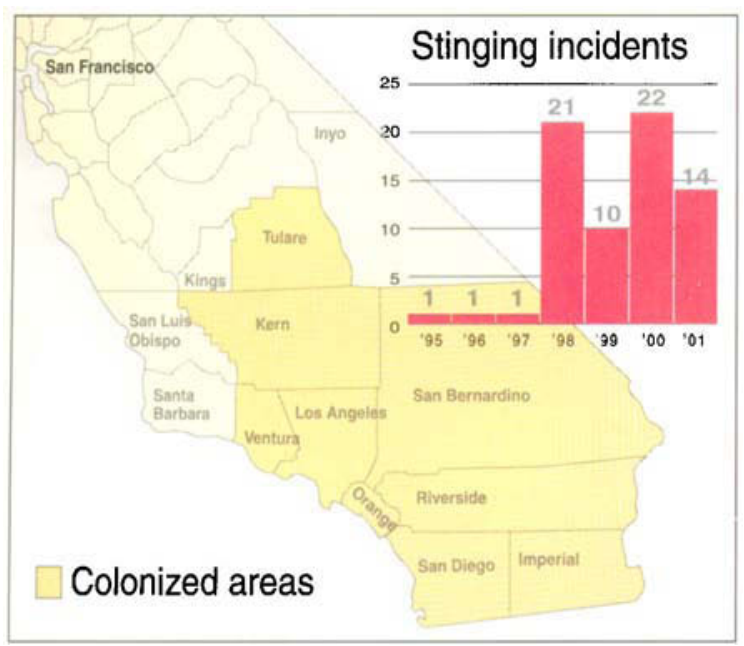

Since entering California in the mid-1990s, Africanized bees have slowly made their way northward; the latest confirmed finds were in Tulare County (map). At the same time, reports of multiple stinging incidents (inset) by Africanized bees have increased. Source: California Department of Food and Agriculture.

tend their hives, but must be vigilant and replace the queens in aggressive colonies.

However, Africanized honeybees tend to colonize niche spaces in urban areas, such as abandoned structures and vehicles, fences and empty boxes. "As the range of the bee has grown, there has been increased contact with areas populated by humans and domestic animals," Kinnee says. "This has resulted in a rising number of stinging incidents."

Seventy incidents of multiple stinging were reported to CDFA between December 1995 and late January 2002, when a 5th-grade boy in West Covina (Los Angeles County) was stung after throwing rocks at a hive.

For more information, go to: www.cdfa.ca.gov/ phpps/pdep/ahb_profile.htm

\section{New wildlife center cleans oiled birds}

The new San Francisco Bay Oiled Wildlife Care and Education Center, which opened its doors in February 2001, faced its first crisis 11 months later when hundreds of oiled birds started turning up in Pacific waters from Point Reyes to Monterey.

As of February, the spill had incapacitated or killed more than 1,500 seabirds, mostly common murres. Hundreds were taken to the center for treatment and rehabilitation; more than 200 birds were released back into the wild.

Located in Cordelia, the facility is one of nine regional centers in the statewide Oiled Wildlife Care Network, which is managed by the UC Davis Wildlife Health Center, a unit of the UC Davis School of Veterinary Medicine. The California Department of Fish and Game (DFG) funds the network with monies assessed on the oil industry.

"Unlike any previous spill in the Bay Area, we now have a facility in place, designed specifically to care for up to 1,000 oiled birds," says Michael Ziccardi, one of four UC Davis wildlife veterinarians who manage animal care for the network. "From the first day, birds have received care as soon as they were found, instead of having to wait, sick and cold, while we put together a rescue center."

When a bird arrives at the 12,000-square-foot, $\$ 2.7$ million center, it is evaluated, treated, washed and rehabilitated by professional staff, with the assistance of volunteers.

The U.S. Coast Guard Marine Safety Office (San Francisco) and the DFG Office of Spill Prevention and Response announced Feb. 8 that the source of the current spill is the SS Jacob Luckenbach, a 468-foot freighter that sank about 17 miles west of the Golden Gate Bridge on July 14, 1953, after a collision.

Oil samples gathered from the ship matched oil found on the feathers of birds and tarballs on the shoreline. Furthermore, oil from the current spill matched samples from similar incidents in 1992, 1997, 1999 and 2001. Altogether, oil from the SS Luckenbach's leaking hull may have killed as many as 10,000 seabirds. Officials are now working on a plan to bring up or seal the freighter.

For more information, go to: www.vetmed. ucdavis.edu/owcn/

\section{- Compiled from U.C. and other news sources}

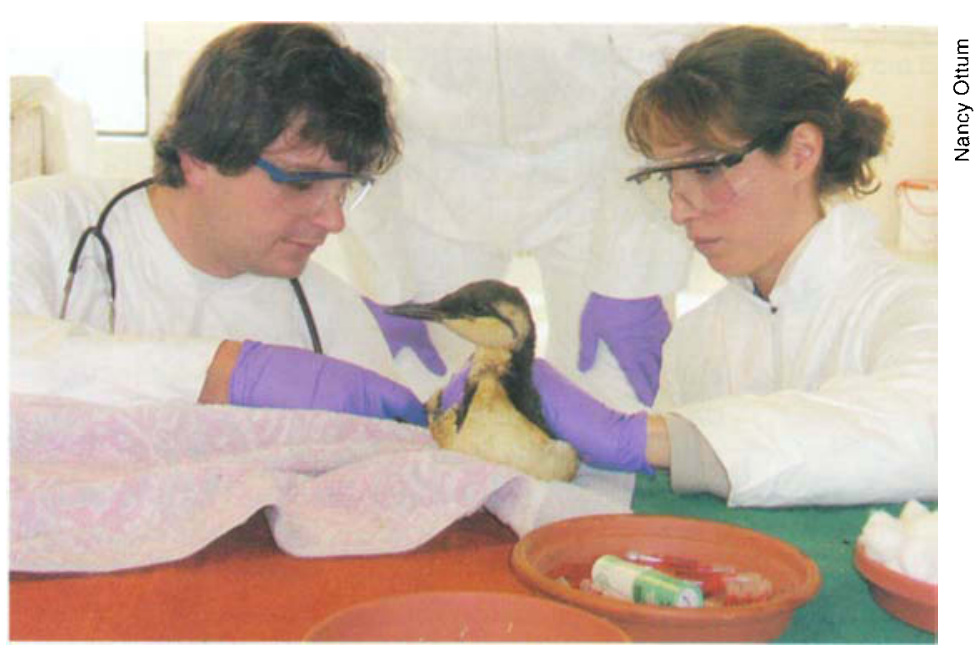

The San Francisco Bay Oiled Wildlife Care and Education Center faced its first crisis when oiled birds began washing up on Bay Area beaches in late November 2001. Above, veterinarians Marty Haulena of the Marine Mammal Center and Christine Kreuder of UC Davis Wildlife Health Center treat a murre. 